\title{
INCLUSÃO E EXCLUSÃO: O RETORNO E A PERMANÊNCIA DOS ALUNOS NA EJA
}

\author{
Jaqueline Cardoso ${ }^{1}$, Maria José de Resende Ferreira ${ }^{2}$ \\ Pós-graduação Lato Sensu em Proeja, Instituto Federal do Espírito Santo \\ E-mail: jaquel2305@hotmail.com, majoresende@yahoo.com.br
}

\section{RESUMO}

Neste trabalho, discutiram-se os motivos que levaram os alunos, jovens e adultos da turma do 8응 Período da Escola Municipal de Ensino Fundamental "Bom Sucesso" São Mateus-ES, a retornarem à escola. Buscou-se também evidenciar o que os professores, pedagogos e gestores dessa escola pensam sobre esse retorno. Foi feita uma discussão na perspectiva da necessidade da garantia do direito à educação, dialogando com Arroyo (2003, 2007), Paiva (2007), entre outros. Empreendeu-se uma pesquisa qualitativa, de caráter exploratório, apresentando um estudo de caso. Os dados foram coletados por meio de questionários e entrevistas aplicados aos alunos, ao corpo docente e aos gestores. Constatou-se que os alunos apresentam histórias similares, possuem famílias numerosas e devido a diversos fatores abandonaram ou foram obrigados a abandonar a escola, mas agora viram a necessidade de retornar. Enxergam a escola como uma possibilidade de ascensão social, de qualificação para alcançarem um bom emprego. Outro ponto a destacar é a necessidade de formação dos professores para lidar com esse público específico, tanto na perspectiva de formação inicial quanto na formação continuada. Os professores se veem como pessoas capazes de influenciar, se não no retorno, na permanência do aluno na escola.

Palavras-chave: EJA. Retorno à escola. Escolarização.

\section{INTRODUÇÃO}

A Educação de Jovens e Adultos (EJA) é a modalidade de Educação sobre a qual muito se tem discutido nos últimos tempos por diversos educadores e pesquisadores. Destes, destaca-se Arroyo (2000), que afirma que a modalidade ainda traz em sua história diversas marcas da negação.

A Lei de Diretrizes e Bases para a Educação Nacional - LDB no 9394 de 1996, que configura a EJA como uma modalidade da Educação Básica nas etapas do ensino fundamental e médio, ainda não foi o suficiente para assegurar aos jovens e adultos uma educação atendendo às suas especificidades. Encontramos respaldo em Arroyo quando este considera ser característica marcante do momento vivido pela EJA "a diversidade de tentativas de configurar sua especificidade" (2007, p.19).

Desse modo, estudos são feitos com o intuito de reconhecer quem são esses jovens e adultos que frequentam as salas da EJA em busca de formação e quais são as expectativas que esses alunos trazem ao retornarem a escola. Foi a partir desses questionamentos que nasceu o desejo de desenvolver essa pesquisa, para conhecer quais os motivos que determinam o retorno dos alunos à escola. Em especial, ao grupo de alunos da EJA da Escola Municipal de Ensino Fundamental "Bom Sucesso", município de São Mateus-ES.

Nos estudos realizados por Cosme (2009) em educação Matemática na EJA no município de São Mateus, constatou-se que as pesquisas realizadas sobre a modalidade são de várias regiões do Brasil,

\footnotetext{
${ }^{1}$ Aluno da Especialização em Educação Profissional Técnica Integrada na Modalidade Educação de Jovens e Adultos (PROEJA - Ifes Campus São Mateus).

${ }^{2}$ Doutora em Educação. Coordenadora e Professora do PROEJA, Ifes Campus Vitória. Membro do Grupo de Pesquisa PROEJA/CAPES/SETECES.
} 
mas nada especificamente no município, logo essa investigação também se faz importante para suprir essa lacuna.

Em contato por um bom tempo com os alunos da Escola municipal de ensino fundamental "Bom Sucesso", verificou-se que os alunos do noturno apresentavam um perfil diversificado: eram alunos jovens e adultos, com idades variadas dos 15 aos 70 anos; alguns trabalhadores que exerciam diferentes funções, outros tantos desempregados. Mas todos com um objetivo em comum: retornar aos estudos.

Que para alguns foram interrompidos quando criança, para outros no semestre anterior, pois haviam desistido meses antes do término do mesmo e para outros ainda, era devido a um convite do gestor, que enxergou a EJA como possibilidade de melhoras para aquele aluno que não cumpria com as exigências da escolaridade "regular" diurna.

Desse grupo que retornou à escola, duas situações me chamaram a atenção: aqueles que frequentaram a escola quando crianças e agora depois de adultos retornavam e aqueles que, a cada semestre, efetivavam a matrícula com o intuito de estudar, mas bastavam poucos dias ou meses de frequência e eles desistiam.

Essas duas situações, de retorno e de continuidade e de retorno e de desistência, cada vez mais inquietavam e assim, outros questionamentos imbricavam-se à primeira situação: Quais são os fatores que influenciam na decisão do retorno à escola? Tem a escola um papel importante na vida dos alunos, na concepção dos mesmos?

A ideia de que a educação é o caminho para superação dos problemas, e que através dela é possível obter sucesso na vida, garantir o futuro, talvez seja uma das motivações de muitos alunos ao retornarem à escola. Nesse contexto, a escola adquire um espaço significativo, com a função reparadora da EJA, que de acordo com o Parecer CEB 11/2000:

[...] no limite que significa não só a entrada no circuito dos direitos civis pela restauração de um direito negado: o direito a uma escola de qualidade, mas também o reconhecimento daquela igualdade ontológica de todo e qualquer ser humano (BRASIL, 2000, p.7).

As expectativas dos jovens e adultos, ao chegarem à escola, são muitas. E o fato de não permanecerem despertam questionamentos que nos levam a refletir sobre nosso papel como educador. Será que nós professores acabamos por frustrar as expectativas dos alunos no retorno à escola?

Paiva (2007) discute a falta de formação dos professores para essa modalidade de ensino. Segundo ela, muitos professores "caem" no âmbito dos sistemas com pouco ou até mesmo nenhum apoio para o trabalho que desejam realizar. Ressalta, ainda, que os discursos e as práticas dos professores mais se afastam do que se aproximam no sentido de alterar, de fato, as relações entre sujeitos aprendizes e entre seu estar no mundo.

Oliveira diz que:

O adulto está inserido no mundo do trabalho e das relações interpessoais de um modo diferente daquele da criança e do adolescente. Traz consigo uma história mais longa (e provavelmente mais complexa) de experiências, conhecimentos acumulados e reflexões sobre o mundo externo, sobre si mesmo e sobre as outras pessoas (OLIVEIRA, 1999, p.16). 
A autora nos chama a atenção para as diferenças existentes entre o adulto, a criança e o adolescente, argumentando que devemos considerar a experiência que o aluno adulto traz consigo ao chegar à escola, pois esse possui maior capacidade de reflexão sobre o conhecimento e até mesmo sobre seu próprio processo de aprendizagem.

A escola é o lugar de concepção, realização e avaliação de seu projeto educativo, uma vez que necessita organizar seu trabalho pedagógico com base em seus alunos, pois ao mesmo tempo em que os alunos usufruem de uma expansão da escolarização, experimentam também o acesso de forma desigual.

É importante conhecer a vida dos alunos, os hábitos de vivência dos mesmos, suas experiências no cotidiano e, a partir daí, construir um projeto de ensino que atenda suas reais necessidades. Muitos desses alunos que a escola recebe vivem uma trajetória escolar cheia de idas e vindas, alguns até mesmo frequentam a escola desde criança e, por razões diversas, acabaram abandonando os estudos e, depois de adultos, retornaram.

E quanto aos alunos da EMEF "Bom Sucesso", quais as suas necessidades, justificativas e o verdadeiro sentido do retorno à escola? A partir desses questionamentos, nossa proposta de trabalho direcionou-se para as investigações das razões que levaram os alunos da EJA da Escola Municipal de Ensino Fundamental "Bom Sucesso", da turma do 8o período, a retornarem à escola.

\section{EJA: DIREITO À EDUCAÇÃO}

O histórico da EJA é marcado por negações (ARROYO, 2007). Pregam-se direitos e igualdade a todos e a todas por meio de legislações vigentes (BRASIL, 1996; 1988; 2000), segundo as quais todas as pessoas que não receberam educação primária ou não concluíram o ciclo completo da educação básica devem ter acesso a esse direito. Apesar desse direito adquirido, constatamos que as desigualdades permanecem, pois agir com igualdade é tratar as pessoas nas suas diferenças e especificidades, isso é, tratar igualmente.

A Declaração de Hamburgo (1997) defende que:

Educação básica para todos significa dar às pessoas, independentemente da idade, a oportunidade de desenvolver seu potencial, coletiva ou individualmente. Não é apenas um direito, mas também um dever e uma responsabilidade para com os outros e com toda a sociedade. É fundamental que o reconhecimento do direito à educação continuada durante a vida seja acompanhado de medidas que garantam as condições necessárias para o exercício desse direito (CONFINTEA, 1997, p. 3).

Logo, favorecer o acesso à escola a pessoas que viveram uma trajetória escolar atribulada - que ao retornarem à escola devem contar necessariamente com a força de vontade - não é o suficiente para garantia desse direito.

Apesar de o Poder Público ter instituído como lei a oferta de educação escolar para jovens e adultos (BRASIL, 1996; 1988) como forma de igualdade a todos os cidadãos, este não o fez dando a devida relevância às particularidades dos sujeitos da EJA, considerando que no espaço da sala de aula desses sujeitos prevalecem a heterogeneidade e a diversidade. Estes alunos e alunas apresentam não só diferenças geracionais, mas também socioculturais, étnico-raciais, de gênero e também de projetos e interesses pessoais.

Em contribuição com a discussão referente à revisão do parecer CNE no. 11/2000, Paiva (s.d.) afirma que "para que o direito se faça prática, é preciso mais do que sua declaração legal". E ainda, com base em dados colhidos pelo Censo 2000, a autora aponta a face cruel da desigualdade, que, 
segundo ela, acontece não apenas ao campo econômico, mas também no tocante ao direito social da educação:

\begin{abstract}
Vários estudos, como o Mapa do analfabetismo realizado pelo INEP, revelam com clareza o quanto a sociedade brasileira tem sido vítima das políticas e conduções de sequentes governantes imóveis ao problema do analfabetismo e da interdição histórica de brasileiros e brasileiras aos instrumentos da leitura e da escrita. A grave situação educacional que os números desse Mapa revelam exige refletir o quanto têm estado equivocadas as políticas públicas para a EJA, restritas, no mais das vezes, à questão do analfabetismo, sem articulação com a educação básica como um todo, nem com a formação para o trabalho, assim como com as especificidades setoriais, traduzidas pelas questões de saúde, gênero, raça, rurais, geracionais etc (PAIVA, s.d.).
\end{abstract}

A autora defende ainda que, mesmo com a universalização do atendimento, o acesso não é o suficiente para dar conta do saber ler e escrever e que os fundamentos das práticas pedagógicas permanecem reproduzindo modelos culturais de classes sociais diversas dos alunos, produzindo o fracasso escolar e a chamada "evasão", fazendo com que, ainda hoje, mesmo que cheguem ao final, não dominem a leitura e nem a escrita. E, nesse sentido

[...] a escola brasileira continua, por assim dizer, produzindo em grande parte 0 analfabetismo e a subescolarização, expulsando dela alunos (e até mesmo professores) que não encontram respostas para o que buscam. Os primeiros, porque não aprendem (segundo os modelos escolares), têm na escola um dos modelos constitutivos das formas de exclusão social, reproduzida sob a forma de preconceitos, rótulos, discriminações, tanto étnicas, quanto sociais e de gênero. Os segundos, porque não conseguem subsistir na condição profissional de professores e abandonam o emprego (PAIVA, s.d).

Nessa discussão, Paiva conclui que todos os esforços que foram realizados no sentido da universalização do atendimento escolar a aqueles que não tiveram acesso na idade própria, não houve êxito nem sequer, de propiciar a leitura e a escrita com competência aos que ficaram à margem.

Nessa mesma perspectiva segue Arroyo (2007, p. 29), ao nos esclarecer que criar alguns espaços para a continuidade de estudos de jovens e adultos populares nada ou pouco fazendo por mudar as estruturas que os excluem do trabalho, da vida, da moradia, de sua memória, da cultura e da identidade coletiva não configurarão a EJA no campo dos direitos.

Na pesquisa realizada por Leão (2006), é apontado que várias reformas na educação básica foram realizadas nas décadas de 1980 e 1990, e que elas, sem dúvida, ampliaram o número de estudantes e os anos de escolaridade das novas gerações, porém, apesar da ampliação quantitativa, as "desigualdades educacionais" continuaram a se reproduzir e a se multiplicar.

Isso nos leva a interrogar se a função equalizadora da EJA que assegura o direito à educação a qualquer indivíduo cuja formação foi sustada, independente da razão e que busca estabelecer a trajetória escolar desse indivíduo de modo a readquirir a oportunidade de um ponto igualitário no jogo conflitual da sociedade (BRASIL, 2000) está sendo cumprida. Precisamos estar atentos para não reduzir direitos a favores, à assistência, à suplência (ARROYO, 2007).

Nesse sentido, deve-se oferecer a esses alunos jovens e adultos, uma educação de qualidade, de forma a atender às necessidades de aprendizagem para que os conhecimentos adquiridos na escola possam propiciar uma visão libertadora, objetivando vencer tudo aquilo que os impede de crescer. 
Sobre esse pensamento Arroyo (2003, p.20) afirma "que não será possível ensinar para participação, desalienação e libertação de classe com os mesmos livros didáticos, a mesma estrutura e a mesma relação pedagógica com que se ensinaram a ignorância e a submissão de classe". E nesse sentido, ele pensa em uma escola que atenda aos reais interesses da classe trabalhadora.

Propiciar a todos a atualização de conhecimentos por toda a vida é a função permanente da EJA (BRASIL, 2000). E mais do que uma função ela é o próprio sentido da EJA, tendo como base o caráter incompleto de ser humano cujo potencial em desenvolvimento e de adequação pode se atualizar em quadros escolares ou não escolares.

A Declaração de Hamburgo (1997) traz que: "O reconhecimento do 'Direito à Educação' e do 'Direito a Aprender por Toda a Vida'" é, mais do que nunca, uma necessidade: é o direito de ler e de escrever; de questionar e de analisar; de ter acesso a recursos e de desenvolver e praticar habilidades e competências individuais e coletivas.

Mas quem são os sujeitos que vêm demandando a educação de jovens e adultos? Quem são esses alunos e alunas? Ou seja, a quem é destinado esse direito à educação que tanto se discute?

Desde que a EJA é EJA esses jovens e adultos são os mesmos: pobres, desempregados, na economia informal, negros, nos limites da sobrevivência. São jovens e adultos populares. Fazem parte dos mesmos coletivos sociais, raciais, étnicos, culturais [...] (ARROYO, 2007, p. 29).

Esse jovem e adulto também é caracterizado no parecer CNE/CEB no 15/98 (apud Parecer CNE/CEB/11/2000, 2000 p.9), tendo esse perfil estendido também aos postulantes do ensino fundamental: "[...] são adultos ou jovens adultos, via de regra mais pobres e com vida escolar mais acidentada. Estudantes que aspiram a trabalhar, trabalhadores que precisam estudar, [...]".

É preciso pensar numa perspectiva diferente de se fazer educação. Pensar estratégias que garantam o direito e que não fuja as reais necessidades dos alunos da EJA:

Trata-se de trajetórias coletivas de negações de direitos, de exclusão de marginalização; consequentemente a EJA tem de se caracterizar como uma política afirmativa de direitos de coletivos sociais, historicamente negados. Afirmações genéricas ocultam e ignoram que EJA é, de fato, uma política afirmativa e, como tal, tem de ser equacionada (ARROYO, 2007, p.29).

Diante do exposto pelo autor, percebe-se que é preciso ir além, na tentativa de garantir os direitos desses sujeitos, uma vez que sua negação é histórica e coletiva. As trajetórias escolares se repetem: avós, pais e agora eles, os alunos, passaram e passam por negações de direitos. É preciso quitar essa dívida. Dívida, pois é assim que Arroyo (2007) encara e afirma que ela é um dever da sociedade, do estado, da pedagogia e da docência.

\section{A ESCOLA: ESPAÇO DE OUTROS SENTIDOS PARA O PÚBLICO DA EJA, ALÉM DA SIMPLES ESCOLARIZAÇÃO}

Mesmo diante dessa situação de direitos negados, existe algo que motiva os alunos, uma vez afastados da escola, a retornarem. Em conversa informal com uma aluna, ela informou que havia parado de estudar, estava somente trabalhando e não gostava da função que exercia, então resolveu voltar a estudar com o intuito de encontrar um emprego melhor. 
Arroyo (2007) discute essa questão do emprego e afirma que pesquisas apontam para o aumento da empregabilidade, porém também ressalta que devemos ficar atentos a essa informação, pois o emprego aumentou mais para a informalidade do que para o trabalho remunerado de forma digna e com garantia de direitos trabalhistas. Salienta, ainda, que os jovens da EJA são os que possivelmente contribuíram para esse aumento; são eles que estão se ocupando do trabalho informal, pois não há vagas no mercado formal e acabam por ficarem com os subempregos ${ }^{1}$.

A escola também adquire outros sentidos além do emprego. Na pesquisa realizada por Leão (2006), já citada anteriormente, sobre um programa de inclusão social para jovens e adultos pobres, moradores da periferia da Região Metropolitana de Belo Horizonte, revelou que mesmo atribuindo pouco valor à escolaridade e à escola, os jovens recorriam sempre a ela, entendendo que era uma das únicas possibilidades de convívio com os outros e também para se protegerem das violências das ruas e das mesmices dos lares.

Assim, a escola adquire importância também no que diz respeito à convivência com as pessoas, na ampliação dos laços das amizades. Funcionando assim como espaço de sociabilidade para as relações socioidentidárias.

\section{FRACASSO E INSUCESSO ESCOLAR NAS CAMADAS POPULARES}

Ao perceber o espaço escolar como lócus de conhecimento e aprendizagem para o público jovem e adulto da EJA, é necessário trazer à tona a discussão do fracasso escolar.

Em todos os momentos de nossas vidas buscamos a perfeição. Traçamos planos e metas para atingir um determinado objetivo, mas algumas situações que não foram imaginadas, logo não foram planejadas, fazem-nos desviar do caminho. Em algumas vezes conseguimos encontrá-lo novamente e aí começamos de novo. Em outras, a trilha deixada por nós foi apagada. E é aí que surge a pergunta: fracassei? Mas o que é fracassar? Meira (2002) nos diz que: "Quando se fala em fracasso, supõe-se algo que deveria ser atingido. Ele é definido por um mau êxito, uma ruína. Porém mau êxito em quê? De acordo com que parâmetro? O que a nossa sociedade atual define como sucesso?"

Discutindo esses questionamentos a respeito do fracasso dentro do contexto escolar, quais são os parâmetros utilizados para concluir que este ou aquele aluno fracassou? Mas quem fracassa é o aluno, o professor ou é a escola? Existe culpado?

Queiroz $(2010$, p.2) discute o tema fracasso escolar, a partir de duas abordagens diferentes: para a primeira, ela busca explicações a partir dos fatores externos à escola, e para a segunda, a partir de fatores internos.

Ela classifica como fatores externos o trabalho, as desigualdades sociais, o aluno e a família. E os fatores internos são a própria escola, a linguagem e o professor. E conclui que:

[...] não existe o fracasso escolar, ou seja, não existe o objeto fracasso escolar, mas sim, alunos em situações de fracasso, alunos que não conseguem aprender o que se quer que eles aprendam, que não constroem certos conhecimentos ou competências, que naufragam e reagem com condutas de retração, desordem e agressão, enfim histórias escolares não bem sucedidas, e são essas situações e essas histórias denominadas pelos educadores e pela mídia de fracasso escolar é que devem ser estudadas, analisadas, e não algum objeto misterioso, ou algum vírus resistente, chamado "fracasso escolar" (CHARLOT, 2000, apud QUEIROZ, 2010, p. 6).

\footnotetext{
${ }^{1}$ Subemprego é uma situação econômica localizada entre o emprego e o desemprego. Ocorre normalmente quando a pessoa não tem recursos financeiros ou formação técnica profissional para se recolocar no mercado de trabalho (IBGE, 2010).
} 
E, assim, pode-se constatar que o fracasso escolar culpabiliza o aluno como o ator principal das mazelas escolares (MOTOKI, 2009). Já Arroyo (2003, p. 25) defende que: "no momento em que passamos a priorizar o fracasso escolar e, sobretudo, o fracasso escolar proveniente das classes subalternas, aí o Estado e sua escola são inocentados, passando a culpar então o próprio povo de sua ignorância."

Seria como atribuir a culpa ao próprio povo por sua pobreza, subemprego, baixos salários. E o governo, na ânsia de diminuir esses altos índices do fracasso escolar, faz com que o aluno permaneça na escola mesmo que esse aluno nada aprenda (ARROYO, 2003). Isso nos leva a concluir que os dados apresentados em relação à escolarização podem apresentar-se mascarados e que, na ânsia de resolver um problema, acaba-se por criar um outro ainda maior: alunos com escolarização, mas que nada sabem. E a situação é que há pouca relação entre a série escolar na qual o aluno se encontra e o conhecimento específico da série.

Nesse sentido, Arroyo (2003) diz que a forma de colocarmos as coisas nos seus devidos lugares, seria retomar a denúncia da escola e do estado fracassado e não tanto do aluno, nem da família ou da comunidade.

\section{PERCURSO METODOLÓGICO}

Essa pesquisa caracteriza-se como uma investigação qualitativa, de caráter exploratório, com apresentação de um estudo de caso e tem como pretensão identificar os fatores que determinam o retorno dos alunos à escola.

O lócus da pesquisa foi a Escola Municipal de Ensino Fundamental "Bom Sucesso", situada num bairro carente do município de São Mateus. A escola funciona desde o ano de 1998 e oferta a educação para jovens e adultos desde essa época. Hoje a escola possui 883 alunos matriculados no Ensino Fundamental, nos três turnos, sendo 80 alunos matriculados na EJA. A turma escolhida para essa pesquisa foi a do 8 o período, por ser ela que acolhe o maior número de alunos.

Os sujeitos da pesquisa são constituídos de dez alunos, sete professores, um pedagogo e um gestor. A coleta de dados foi feita por meio de questionário com questões fechadas, com o intuito de traçar o perfil socioeconômico de cada aluno. As questões abertas visaram conhecer a trajetória dos alunos, os motivos pelos quais não foi possível prosseguirem os estudos quando criança, e o/os motivo(s) do retorno. As questões visaram também compreender a percepção do aluno quanto à importância da escola na vida dos mesmos.

Para os outros sujeitos, foi utilizada a entrevista semiestruturada. Primeiramente, queria-se conhecer o perfil desses profissionais que trabalham de forma direta ou indiretamente com os alunos. Posteriormente, as questões abordaram perguntas abertas, com a finalidade de averiguar a opinião dos professores no retorno do aluno à escola, buscando compreender se eles reconhecem e consideram importante sua participação nesse processo.

\section{DISCUSSÃO DOS RESULTADOS}

\section{0 retorno à escola}

Dos alunos entrevistados, todos eles apresentam históricos similares. São alunos que vieram de famílias numerosas. Devido a esse fato, deixaram a escola muito cedo para trabalhar. Hoje são casados e possuem em sua maioria mais de dois filhos. Dos que trabalham, exercem funções tais como: cozinheira, pedreiro, auxiliar de serviços gerais, entre outras atividades. A renda familiar desse grupo não excede a três salários mínimos. 
Na turma pesquisada, encontrou-se parte dos alunos que estudaram quando criança e agora adultos, desde que retomaram os estudos não pararam mais. Uma vez que decidiram retornar, não ficaram nesse processo de idas e vindas. Esse grupo é formado por alunos de mais idade.

Por outro lado, temos alguns alunos que tiveram um primeiro contato com a escola quando crianças, porém, por diversos motivos, abandonaram ou foram obrigados a abandonar os estudos. E agora adultos retornaram, mas não permanecem. Matriculam-se todo semestre e nunca concluem os estudos.

Ao interrogar os alunos sobre o porquê de terem retomado os estudos, surgiram respostas comuns. Os motivos vão desde a realização de um sonho à obtenção de qualificação para o mercado de trabalho, entre outras motivações.

\section{OS MOTIVOS}

\section{Socialização}

Dona Maria ${ }^{2}$ foi privada quando criança de frequentar a escola, pois segundo ela os pais moravam em um lugar de difícil acesso e não havia escolas na região. E também depois de adulta, pois, estando casada, teve que trabalhar fora e ainda cuidar dos filhos e, posteriormente, dos netos. A escola continuou sendo algo não possível em sua vida. Porém mais tarde, com os filhos já crescidos e não tendo mais que trabalhar fora, retornou à escola.

Quando questionada por que retornou, Dona Maria respondeu que era para adquirir mais conhecimento, porém relatou que o que a fez procurar a escola novamente foi um fato sucedido entre ela e seu neto de sete anos de idade.

Segundo ela, quando tentava ajudá-lo em suas tarefas escolares, mesmo sem saber muito do conhecimento adquirido na escola, ao escrever o seu nome (do neto), ela o fez de maneira errada e logo foi interpelada pelo mesmo que dizia que nem o nome dele ela sabia escrever, por isso devia ir para escola. E foi isso que ela fez. Hoje Dona Maria está cursando o 8o período, tendo retornado no 4 ㅇ período e afirma que não pretende parar, já está pensando em cursar o Ensino Médio.

Ferreira (2007), nos seus estudos sobre escolarização feminina aponta que:

[...] por tradição histórica, a mulher teve sua existência atrelada à família, o que lhe dava a obrigação de submeter-se ao domínio masculino, seja pai, esposo ou mesmo o irmão. Sua identidade, segundo esses estudos, foi sendo construída em torno do casamento, da maternidade, da vida privada-doméstica, fora dos muros dos espaços públicos. E por essa tradição, construída historicamente, a mulher se viu destituída de seus direitos civis. Não podia participar de uma educação que fosse capaz de prepará-la para poder administrar sua própria vida e de ter acesso às profissões de maior prestígio. Assim, por um longo período histórico, a família, a igreja e a escola, elementos inerentes a esse processo, enquanto instituições, vão sustentar esse projeto moralizador, tutelando a mulher ao poder econômico e político do homem brasileiro (FERREIRA, 2007, p. 15).

A autora ainda aponta que, historicamente, a escola esteve interditada às mulheres, mas foi por meio dessa instituição que as mesmas conseguiram romper com as determinações da ideologia vigente e por meio da escolarização e profissionalização que alcançaram os espaços públicos (2007).

\footnotetext{
${ }^{2}$ Os nomes dos sujeitos apresentados são fictícios.
} 
Essa situação vivenciada por Dona Maria - e por muitas outras Marias por este país afora - remetenos a Arroyo (2007):

[...] antes do que portadores de trajetórias escolares truncadas, eles e elas carregam trajetórias perversas de exclusão social [...]. As trajetórias escolares truncadas se tornam mais perversas porque se misturam com essas trajetórias humanas (ARROYO, 2007 p.24).

Logo, a negação do direito à escolarização, acarreta a negação de tantos outros, inclusive de uma participação mais efetiva na vida dos seus familiares, provocando até mesmo constrangimentos, que por sorte, no caso de Dona Maria foi revertido de maneira positiva.

\section{0 emprego}

A falta de escolarização nega também o acesso aos empregos e principalmente aos empregos melhores remunerados. $E$, nesse sentido, o sonho de ter uma profissão que garanta uma vida digna para si e também para os familiares contribuem para que os alunos retornem à escola. Para o Senhor Amarildo ( 8 o período), que hoje trabalha como vigia de casas, o estudo é essencial no sentido de trazer melhorias: "Voltei a estudar, porque tenho um objetivo, terminar os meus estudos para dar uma vida melhor à minha família".

A questão de garantir um melhor emprego não é preocupação somente do Sro Amarildo. Leandro é um jovem de 20 anos, reprovou algumas vezes. Há cinco anos vivencia esse processo de idas e vindas e tenta mais uma vez terminar a série final do ensino fundamental: "Pensei que só trabalhar valia a pena, mas se eu não estudar vai chegar um dia que não vou conseguir emprego por falta de estudo" (LEANDRO, 8ำ.)

Para Leandro, agora a escola possui significado, dessa forma ele mais uma vez a ela retorna. Assim, tanto para Leandro como para outros jovens da EJA "a escola é uma experiência em que entram em ações valores, projetos de vida, expectativas [...]" (LEÃO, 2006, p.36).

E esse mesmo autor afirma ainda que "[...] A motivação do jovem diante da escola se dará em face da forma como cada um elabora sua experiência de crescer em meio à desigualdade social e do significado que a educação irá adquirir em sua vida" (LEÃO, 2006, p.36).

Nesse sentido, seria necessário pensarmos nas seguintes questões: Quais são as relações construídas entre o trabalho e a escola na sala de aula? Que níveis de saber a escola tem trabalhado de maneira a atender a esse aluno trabalhador para se desenvolver como tal? Qual é a importância dada pela escola ao aluno da EJA enquanto trabalhador ou o que deseja ser?

Que o mercado de trabalho, com o grande avanço da tecnologia está cada dia mais exigente, isso é sabido por todos e principalmente pelos alunos da EJA. Não basta somente certificação; é preciso desenvolver habilidades, apresentar estratégias, ter capacidades de tomar decisões. Algumas características de alunos pouco escolarizados levam-nos a concluir que cabe à escola desenvolver essas habilidades exigidas pelo mundo do trabalho. Mas Oliveira (2004), em seus estudos, aponta que questões desse tipo parecem estar relacionadas à escola, mas não é algo homogêneo, pois podemos perceber que entre sujeitos que são escolarizados, há aqueles que não apresentam essas características e entre sujeitos pouco escolarizados há aqueles que as apresentam.

Mas isso não exime a escola da responsabilidade no desenvolvimento intelectual do aluno. Isso nos leva a pensar que é preciso desenvolver diferentes atividades com nossos alunos, uma vez que nenhum aluno é igual ao outro, logo apresentam maneiras diferentes de se desenvolverem socialmente e intelectualmente. 
Nesse sentido, Oliveira (2004) nos chama atenção para enxergar os jovens e adultos como sujeitos concretos que se encontram na sala de aula e que sejam, a partir desse ponto, objetos de conhecimentos aprofundados, por meio dos quais poderia ser estabelecido um diálogo com os instrumentos e modos de pensar que são próprios da escola. Logo aproximaríamos a escola e o trabalho, e todas as atividades desenvolvidas pelos alunos, tornando-os "[...] como sujeitos humanos plenos, em constante constituição por meio da imersão em situações concretas de construção de significações [...]" (OLIVEIRA, 2004, p.228).

Os professores são peças importantes nesse processo de (re) significação da educação na vida dos alunos. É necessário que os professores abordem questões relativas ao trabalho e suas diversas formas; que pensem num currículo que atenda essas necessidades, perceptíveis nos alunos ao retornarem a escola.

Sobre a qualidade dos conteúdos e métodos utilizados com esses alunos trabalhadores, reflete Arroyo (2003, p. 19):

“[...] os conteúdos e métodos e a organização escolar foram concebidos mais para formar os cidadãos como trabalhadores semianalfabetos, submissos e desqualificados, do que ativos e participantes na vida social e na organização do trabalho $[\ldots]^{\prime \prime}$.

É necessário compreender e valorizar a importância - que por enquanto ainda é dada pelos alunos da escolarização como consequência do sucesso no mundo do trabalho, para que assim o retorno à escola venha realmente fazer sentido a esses alunos e que faça com que sintam o desejo de prosseguir cada vez mais, evitando a evasão:

\begin{abstract}
A disparidade entre a visão que o aluno tem do que seja a escola e uma educação que efetivamente sirva esse aluno pode gerar conflito. Não são incomuns casos até de desistência do curso. Não encontrando uma escola que corresponda às suas expectativas, o aluno se frustra e como não é uma criança que os pais levam obrigatoriamente à escola, acaba abandonando o curso. (CARLOS e BARRETO, 2005, p. 67, apud COURA, 2008).
\end{abstract}

Diante disso, é preciso ter o cuidado para que a EJA não seja mais uma a contribuir para esse histórico de negação de direitos já vivenciados pelos alunos.

\title{
Cidadania
}

"Tudo que um ser humano precisa na vida para ser um bom cidadão" é a resposta dada por um aluno quando questionado sobre o significado da escola. Percebe-se que esse aluno entende que mais do que transmitir conhecimentos "escolares", a função da escola também é prepará-lo para ser cidadão. E o que é ser cidadão?

Ser cidadão é ter direito à vida, à liberdade, à propriedade, à igualdade perante a lei: ter direitos civis. É também participar no destino da sociedade, votar, ser votado, ter direitos políticos. Os direitos civis e políticos não asseguram a democracia sem os direitos sociais, aqueles que garantem a participação do indivíduo na riqueza coletiva: o direito à educação, ao trabalho justo, à saúde, a uma velhice tranquila (CODIC- Coordenadoria dos Direitos da Cidadania). 
Nesse sentido, a escola se configura como preparação para vida. É ela que supostamente permeia os caminhos que devem ser percorridos por esses jovens e adultos, que ao retornarem à escola, já possuem certo conhecimento de vida e, que, possivelmente, não obtiveram sucesso nos caminhos trilhados até o momento do retorno.

Logo, a escola precisa se reestruturar. Traçar novos caminhos ${ }^{3}$, pois aqui ela assume mais um papel muito importante: formar pessoas capazes de atuarem no mundo em que vivem e assim poderem ser chamados de cidadãos. A afirmação de Arroyo aponta nessa direção, a saber:

A EJA como espaço formador terá de se configurar reconhecendo que esses jovens e adultos vêm de múltiplos espaços deformadores e formadores onde participam. Ocupam espaços de lazer, de trabalho, cultura, sociabilidade, fazem parte de movimentos de luta pela terra, pelo teto e pelo trabalho, pela cultura e pela dignidade (ARROYO, 2007, p. 25).

E esse mesmo autor nos convida a olhar esses jovens e adultos de maneira que reconheçamos e entendamos seu protagonismo, pois esses alunos não têm apenas trajetórias escolares truncadas. São vítimas de violência, da falta de emprego, da falta de horizontes, enfim, são vítimas da exclusão social. E por isso é preciso mudar o olhar, vermos mais que alunos ou ex-alunos em trajetórias escolares. Dessa forma, valorizar suas experiências, a forma como percebem a realidade é um ponto de partida para que se construam novos saberes nesses espaços educacionais.

Foi questionado aos alunos: Como você gostaria que fosse a escola? As respostas não apontaram para mudanças no sentido físico da escola e nem em relação ao corpo docente. Aproveitaram esse espaço para elogiar tantos os professores, quantos os coordenadores e diretora, afirmando que todos são ótimos. Só acrescentaram que gostariam muito que a escola oferecesse, além do ensino fundamental, o ensino médio, pois isso facilitaria a continuidade aos estudos, uma vez que as escolas que ofertam o ensino médio são muito distantes.

\section{A participação dos professores nas idas e vindas}

Dos professores entrevistados todos possuem formação acadêmica com especialização, porém mais de $50 \%$ deles não possuem curso específico para atuarem na EJA. Isso se comprova entre os professores que possuem pouco tempo de atuação nessa modalidade de ensino - de quatro meses a dois anos. Já os que trabalham há mais tempo, de quatro a dez anos, todos eles possuem curso na área.

Isso nos leva à questão discutida anteriormente quando Paiva (2007) ressalta a pouca formação dos professores que atuam na EJA. Não é exigido curso de formação específica para os professores que atuam com essa modalidade de educação.

Porém, não se deve culpabilizar os professores por não ter tal formação, pois, a pesquisa realizada por Rodrigues e Dalla (2007) sobre o Curso PROEJA ${ }^{4}$, que é um curso de formação para professores que atuam na educação de jovens e adultos, mostrou que muitos professores buscam a formação. Quando interrogados sobre os motivos que os levaram a buscar o curso, alguns responderam que eram para aprimoramento profissional, outros para poderem conhecer e aprender sobre a EJA e

\footnotetext{
${ }^{3}$ Em todas as escolas da rede municipal de São Mateus onde são oferecidas EJA, existia até no semestre anterior uma profissional chamada de Mãe Social. A ela cabia a responsabilidade de cuidar dos filhos dos alunos da EJA enquanto estes estudavam. Porém, nesse semestre, essa assistência não está sendo oferecida. E de acordo com os alunos isso contribuiu para o afastamento de muitas alunas que não têm com quem deixar seus filhos durante a noite para poderem estudar, além de ter impossibilitado o acesso de outras.

4 "A maioria dos sujeitos educadores de EJA se forma na prática, com a enorme criatividade que nos caracteriza" (GOERNE, 2000, p. 9, apud OLIVEIRA, 2004).
} 
sobre as possibilidades de ensinar. E, ainda, alguns responderam que era pela necessidade de trabalhar com o público. Logo se vê que há uma busca pela formação.

As autoras questionaram também aos professores se a forma como o curso se desenvolveu possibilitou eixos de reflexão sobre a prática. Eles responderam que até houve reflexão, porém partindo da análise de sua atuação, ressaltando que não foram consideradas as peculiaridades da EJA.

Nesse sentido, observa-se que a falta de formação ou a formação que parte somente daquilo que já foi vivenciado talvez venha a interferir no relacionamento entre o professor e o aluno da EJA. $O$ professor não sabendo como lidar com esse público, que já não é mais criança, que já traz uma bagagem de histórias vivenciadas, pode transmitir, na sua maneira de lecionar, uma impressão equivocada aos seus alunos.

A forma como os professores lecionam e tratam seus alunos influencia na opinião desses a respeito daqueles, que podem ser elogiados ou até mesmo criticados ${ }^{5}$. Na pergunta realizada aos alunos sobre como gostariam que fosse a escola um aluno respondeu que: "A escola pra mim só teria que mudar em questão do ensino, porque tem muitos professores que estão ali só porque são pagos $e$ não porque gostam de ensinar. Acho que todos têm que fazer o que gosta" (LEONARDO, 8o p).

O desabafo desse aluno vai de encontro com a fala de uma professora, que afirma que "para incentivar os alunos é preciso apresentar profissionais alegres que demonstrem verdadeira vontade de ensinar. Toda vez que venho para o trabalho, tenho sempre esse cuidado, de demonstrar sempre alegria para os alunos" (PROFESSORA A).

Nesse contexto, a professora lança um olhar sobre si mesmo e sobre o que pode provocar em seus alunos. Tem a preocupação de estar e de parecer sempre disposta, mesmo que esse não seja o caso. Os professores se veem no processo de formação dos alunos. Quando questionados sobre o que a escola pode fazer para evitar as idas e vindas dos alunos da EJA, apontam para si essa responsabilidade. Como sugestões os professores destacaram:

- Manter o diálogo entre os alunos com o intuito de estreitar os laços;

- Buscar e promover projetos que motivem os alunos;

- Conscientizar os alunos da importância dos estudos para o desenvolvimento intelectual e profissional;

- Proporcionar aulas dinâmicas, relacionando conteúdo e prática.

A gestora destacou que já são desenvolvidos projetos e utilização da informática para ajudar nesse processo. Porém, ela ressalta que é preciso ter certo cuidado para evitar o excesso de aulas diferentes, pois muitos alunos adultos não gostam, consideram perda de tempo. E o que serviria para promover a permanência acaba promovendo a desistência.

Percebe-se então nas sugestões dadas pelos/pelas professores/professoras, o que sugere Oliveira (2004), a compreensão de que eles são os sujeitos que entre teorias e práticas, vão construindo o conhecimento necessário para lidar com esse público:

O que requer de fato incorporar a compreensão de que esses professores, como os demais profissionais da educação, são sujeitos do conhecimento e possuem saberes específicos, um saber-fazer que, no cotidiano de suas práticas, vão sendo desafiados a construir, no contato com os diferentes grupos com que atuam (OLIVEIRA, 2004, p.4).

\footnotetext{
${ }^{5} \mathrm{~A}$ maioria dos entrevistados elogiou o corpo docente. Houve somente um caso, em que se criticou a má vontade por parte dos professores para lecionar.
} 
E nesse sentido, é importante trazer à baila o pensamento da autora Kaefer e Silva (2008) quando afirma que é preciso que os professores assumam seu papel e tenham acima de tudo humildade, decência e seriedade, sem demonstrar apatia. E é nessa humildade que possamos ter coragem tanto para renunciar quanto para avançar um pouco mais, porém entendendo que, se decidirmos permanecer, é preciso sempre rever as nossas práticas, pois estamos lidando com sujeitos sensitivos também.

\section{CONSIDERAÇÕES FINAIS}

Durante todos esses anos em que a Escola Municipal Bom Sucesso oferta educação para jovens e adultos, muitos alunos já passaram pelos bancos dessa escola. Foram muitos alunos que nesse processo de idas e vindas, optaram por retornar e concluir os estudos. E agora, diante dessa pesquisa, pode-se entender os motivos que os fizeram decidir pelo retorno.

Diante das análises nas falas dos alunos, foi possível inferir que eles consideram que a educação é o meio mais importante e até mesmo o mais acessível para se conseguir trabalho e reconhecimento na sociedade. E que apesar das dificuldades passadas e presentes, os alunos ainda veem a escola com olhar de esperança. Esperança de conseguir um "emprego melhor", ou até mesmo de conseguir o "primeiro emprego" e, assim, poder ter melhores condições de vida.

Assim a EJA se configura como possibilidade de elevação de escolaridade e também elevação da qualificação dos alunos trabalhadores ou dos que venham a ser. E dessa forma pode-se inferir que é por isso que à escola retornam, pois há sempre esperanças de mudar, de superar a condição de excluídos.

Para outros alunos, a escola é aprendizado, é a forma de ser inserido na sociedade e até mesmo no convívio familiar como foi o caso de Dona Maria.

Nas análises teóricas percebeu-se o quanto é importante a formação dos professores para atuarem com a EJA. O quanto é importante se os mesmos tivessem essa preparação teórica, que buscassem base em diversos autores com o intuito de mudar o olhar sobre esses alunos, enxergando na profissão não só mais uma maneira de "ganhar a vida", mas, sim, como possibilidade de mudar vidas.

Em relação às entrevistas feitas aos/as professores/professoras, pode-se dizer que todos gostam de atuar com esse público, consideram gratificante presenciar o crescimento e a formação dos alunos que se dá continuamente, principalmente entre os de mais idade, que também demonstram alegria a cada novo aprendizado.

A gestora e as coordenadoras preocupam-se em fazer com que os alunos retornem à escola. De acordo com a coordenadora, houve uma época em que se fazia uma carta endereçada ao aluno que abandonava a escola, questionando os motivos e pedindo que ele retornasse. Porém, com o passar do tempo, isso acabou ficando para trás.

O que se pretendeu foi destacar os motivos das idas e vindas dos alunos, e quando não relacionados, ao trabalho, a família, os motivos são de ordem pessoal. Tanto do retorno, quanto da desistência. Mas que a escola pode interferir sim, tanto de maneira positiva, quanto negativa. Logo, é preciso estar atentos com nossas práticas no nosso processo de ensinar.

\section{REFERÊNCIAS}

ALMEIDA, Maria Lúcia Silva. Sujeitos não-alfabetizados: sujeitos de direitos, necessidades e desejos. In: SOARES, Leôncio (org.). Aprendendo com a diferença: estudos e pesquisas em Educação de Jovens e Adultos. Belo Horizonte: Autêntica, 2003.

ARROYO, Miguel Gonzalez. (org.). Da escola carente à escola possível. São Paulo: Edições Loyola, 2003. 
ARROYO, Miguel Gonzalez. Juventude, produção cultural e Educação de Jovens e Adultos. In: Leôncio (org.) Diálogos na educação de jovens e adultos. Belo Horizonte: Autêntica, 2007.

COSME, Gerliane Martins. Da formação no curso de licenciatura em matemática de São Mateus ao profissional da EJA. Dissertação de Mestrado em Educação. Vitória: UFES, 2009.

BRASIL. CONSELHO NACIONAL DE EDUCAÇÃO (BRASIL). Parecer №. 11/2000 - CEB - Aprovado em 10 de maio de 2000.

CARLOS, José e BARRETO, Vera. Um sonho que não serve ao sonhador. Disponível em: $<$ www.diaadia.pr.gov.br>. Acessado em 25 de Setembro de 2010.

CONFITEA (Conferência Internacional sobre Educação de Adultos). Declaração de Hamburgo: agenda para o futuro. 1999. Brasília: SESI/UNESCO. Disponível em: <http://www.dominiopublico.gov.br/download/texto/ue000006.pdf>. Acesso em: abr. 2009.

DALLA, Mônica Rambalducci Sily e RODRIGUES, Fernanda Ribeiro Pinto. PROEJA: Os desafios na construção de pontes entre as propostas legais e a formação docente. Monografia (Especialização). Curso de Especialização do Programa Nacional de Integração da Educação Profissional com a Educação Básica na Modalidade da Educação de Jovens e Adultos. CEFETES, Vitória, 2007.

FERREIRA, M. J. de R. Escolarização e gênero feminino. Um estudo de caso no EMJAT/CEFETES. 2007. 98 f. Monografia (Especialização). Curso de Especialização do Programa Nacional de Integração da Educação Profissional com a Educação Básica na Modalidade da Educação de Jovens e Adultos. CEFETES, Vitória, 2007.

IBGE. Instituto Brasileiro de Geografia e Estatística - www.ibge.gov.br. Acesso em 15/10/2010.

KAEFER e SILVA, Maria Teresinha. Um olhar sobre a postura do educador da Educação de Jovens e Adultos numa perspectiva freiriana - 2008. Revista da Educação de Jovens e Adultos. Disponível em www.reveja.com.br. Acesso em outubro de 2010.

LEÃO, Geraldo Magela Pereira, Experiências da desigualdade: os sentidos da escolarização elaborados por jovens pobres. Universidade Federal de Minas Gerais, 2006.

MEIRA, Michelle de Castro. Fracasso Escolar: de quem é a culpa? Disponível em: http://www.divinopolis.uemg.br/revista/revista-eletronica3/sumario.htm Acessado em 30 de setembro de 2010.

MOTOKI, Celina Keiko Suguri. Fracasso escolar: Entre encantos e desencantos da escolarização sob o olhar dos educandos do PROEJA - IFES. 58 f. Monografia (Especialização). Curso de Especialização do Programa Nacional de Integração da Educação Profissional com a Educação Básica na Modalidade da Educação de Jovens e Adultos. CEFETES, Vitória, 2009.

OLIVEIRA, Marta Kohl de. Jovens e adultos como sujeitos de conhecimento e aprendizagem. Revista Brasileira de Educação. Anped: set/out/nov/dez de 1999. oo 12.

OLIVEIRA, Marta Kohl de. Ciclos de vida: Algumas questões sobre a psicologia do adulto. Educação e pesquisa, maio-ago/vol 30, no 002.2004.

OLIVEIRA, Edna Castro. Sujeitos-professores da EJA: visões de si mesmos em diferentes contextos e práticas. Salto para o futuro/ EJA 2004.

O QUE É CIDADÃO? - www.codic.pr.gov.br/modules/.../conteudo.php - acesso em 25/09/2010. 
PAIVA, Jane. Direito à Educação de Jovens e Adultos: concepções e sentidos. In: 29A. REUNIÃO ANUAL DA ANPED. Anais... Caxambu, MG: ANPED. 2007.Disponível em:< http:/ www.anped.org.br > Acesso em: 21 de Setembro de 2010.

PAIVA, Jane. Direito à Educação para quem? Sem data. Disponível em:<http://www.forumeja.org.br/>.Acesso em 20 Setembro de 2010.

QUEIROZ, Lucileide Domingos. Um estudo sobre a evasão escolar: para se pensar na inclusão escolar. In: 25A. REUNIÃO ANUAL DA ANPED. Anais... Caxambu, MG: ANPED. Disponível em: www.anped.org.br/reunioes/25/lucileidedomingos queirozt13.rtf. Acessado em 21 de setembro de 2010. 
